\title{
Experimental behavior of FRP strengthened masonry arches
}

Daniel V. Oliveira ${ }^{1}$, Ismael Basilioo ${ }^{2}$ and Paulo B. Lourenço ${ }^{3}$

ISISE, Department of Civil Engineering, University of Minho, Guimarães, Portugal

ABSTRACT: This paper deals with the experimental behavior of solid clay brick masonry arches strengthened with glass fiber reinforced polymer composites. Twelve half-scaled segmental masonry arches subjected to a load applied at the quarter span were tested under displacement control up to failure. The arches were built using handmade low strength bricks and a commercial lime-based mortar, trying to mimic ancient structures. Besides reference unreinforced arches, five different strengthening arrangements, including the use of spike anchors, were studied. The experimental results provide significant information for validation of advanced numerical models and analytical tools, and for code drafting. The experimental results also show that: (1) only continuous strengthening strategies are able to prevent typical local failure mechanisms of unreinforced arches; (2) strengthening at the intrados is the most effective option to increase strength; (3) strengthening applied at the extrados provides the higher deformation capacity prior to failure, endowing arches with considerable ductility behavior.

KEYWORDS: Masonry arches; Fiber reinforced polymers; Strengthening; Failure mechanisms; Testing

${ }^{1} \mathrm{PhD}$, Assistant Professor, Department of Civil Engineering, University of Minho, Azurém, P-4800-058 Guimarães, Portugal. Phone: +351 253510 247, fax: +351 253510 217, email: danvco@ civil.uminho.pt

${ }^{2} \mathrm{PhD}$, Department of Civil Engineering, University of Minho, Azurém, P-4800-058 Guimarães, Portugal. Phone: +351 253510 247, fax: +351 253510 217, email: ibasilios@gmail.com

${ }^{3} \mathrm{PhD}$, Professor, Department of Civil Engineering, University of Minho, Azurém, P-4800-058 Guimarães, Portugal. Phone: +351 253510 209, fax: +351 253510 217, email: pbl@civil.uminho.pt 


\section{INTRODUCTION}

As part of the cultural heritage, historical masonry constructions require particular attention. Through centuries, these structures have accumulated structural damage caused by loading, environmental actions, soil settlements, lack of maintenance, as well as due to exceptional events as earthquakes. Taking into account that many of these masonry structures are of considerable architectural and cultural value, the definition of cost effective repair/strengthening procedures complying with structures' significance and able to reestablish safety and lost performances (ICOMOS 2001) are current issues in scientific research.

Among the materials used to repair or to upgrade existing civil engineering structures, there has been an increasing interest in the use of fiber reinforced polymer (FRP) composites, either in the form of externally bonded or near-surface mounted reinforcements. FRP exhibits several advantages, such as low specific weight, corrosion immunity, high tensile strength, adaptability to curved surfaces and ease of application, which makes it attractive and cost effective to be used in repair/strengthening works. However, FRP is a brittle material and its behavior has to be further investigated, particularly with respect to durability.

Schwegler (1994) and Saadatmanesh (1994) were the first researchers to analyze the use of FRP for the strengthening of masonry structures. Following these initial studies, several experimental works have been carried out (Ehsani et al. 1997, Kolsh 1998, Triantafillou 1998, Albert et al. 2001) showing that this technique is effectively valid as an option to repair or strengthen masonry structures, in particular arched ones (Valluzzi et al. 2001, Briccoli Bati and Rovero 2001, Foraboschi 2004, Briccoli Bati et al. 2007). These research works address carbon and glass fibers. However, for the strengthening of old masonry structures, characterized by low strength and low stiffness values, the use of glass fibers (GFRP) seems preferable. When compared with carbon fibers, the lower axial stiffness of GFRP materials leads to less mechanical compatibility problems in combination with masonry and, thus, has the advantage of reducing stress concentrations along the (wider) GFRP-masonry interface. Experiments have shown that masonry arches strengthened with glass fibers exhibit better global ductility characteristics (Valluzzi et al. 2001).

Several experiments performed on masonry arches strengthened with composite materials are reported in literature, but the influence of the different strengthening arrangements on the structural behavior is not totally clear. As discussed later in the paper, it is not consensual which strengthening arrangement provides the higher increase in collapse load or the best ductility behavior. In addition, some of the test setups used are quite complex if an advanced numerical modeling is pursued. Therefore, tests involving complex setups and 
procedures should be complemented with tests based on simpler setups, where the influence of the different parameters can be controlled much better.

This paper reports and discusses the results of an experimental program on the behavior of brick masonry arches, with and without different FRP strengthening arrangements, carried out at University of Minho. The experiments were carried out on twelve half-scaled models subjected to a monotonically increasing vertical displacement applied at the quarter span and up to failure. Different strengthening strategies were tested, aiming at understanding and clarifying the effect of the FRP arrangement on the structural behavior of the arches, at both local and global levels. This experimental work was designed to attain the following main objectives:

- characterization of the structural behavior of unreinforced and strengthened masonry arches monotonically loaded, including the softening regime, which is usually absent from literature;

- assessment of the influence of the strengthening arrangement on the mechanical behavior and failure mode, in terms of load capacity, ductility and failure modes;

- contribution to the establishment of a reliable database on the experimental behavior of FRP strengthened masonry arches, able to be used for the calibration of both analytical and numerical tools.

\section{BEHAVIOR AND FAILURE MODES OF MASONRY ARCHES}

\section{Unstrengthened arches}

Assuming that masonry has zero tensile strength, which can be justified by its relatively low tensile strength, an arched masonry structure is kept in compression as long as the thrust line is kept inside the mid-third central core. Movement of the thrust line outwards the central core at a given cross-section implies the formation and consequent opening of a crack at the cross-section. In this case, safety is maintained as long as the thrust line is kept inside the thickness of the arch. Upon increasing load, crack development will lead to the formation of a hinge located on the boundary of the cross-section, either at the intrados or extrados of the arch. Then, the formation of successive hinges leads eventually to the development of a hinge-based mechanism that causes arch failure. This means that unstrengthened masonry arches fail usually by the occurrence of a number of hinges enough to form a mechanism (Heyman 1982). Figure 1 represents the typical four-hinge mechanism of a masonry arch submitted to an asymmetrical concentrated load. 


\section{Strengthened arches}

The existence of FRP reinforcement, usually externally bonded to the masonry substrate, changes completely the structural behavior of a masonry arch. The FRP, which provides an enhanced flexural capacity due to its tensile strength capacity, may prevent the aforementioned hinge formation, thus changing the failure mode significantly. Now, the thrust line may safely move outwards the thickness of the arch. For the arch illustrated in Figure 1, and considering FRP strengthening located either at the extrados or intrados of the arch, only two hinges at supports and a third hinge located on the strengthened side of the arch are able to develop. Therefore, the fourth hinge is prevented from occurring, transforming the arch into an isostatic structure.

The increase of the flexural capacity makes possible the development of new failure modes, unlikely to happen in unstrengthened arches. Due to the high FRP tensile strength, the compressive stresses in masonry may now assume higher values so failure of the arch caused by masonry crushing has to be considered. The outward movement and the larger inclination of the thrust line with respect to the cross-section imply the development of high shear stresses in masonry, therefore sliding failure along a joint may also occur. Moreover, the curved shape of arches strengthened at the intrados originates stresses in the FRP with a component normal to the masonry substrate, which may cause the detachment of the FRP from masonry. Sliding between the externally bonded FRP and masonry is usually neglected because shear stresses at the FRP-masonry interface are of minor magnitude (Valluzzi et al. 2001). Also, FRP tensile failure is not likely to occur due to its high tensile strength, usually hundreds of times larger than the masonry compressive strength.

\section{EXPERIMENTAL STUDY}

Aiming at replicating traditional masonry structures, solid clay bricks and a lime-based mortar were selected to build the scaled arches. For that purpose, bricks of dimensions $100 \times 50 \times 25 \mathrm{~mm}^{3}$ were fabricated on purpose for this project, whereas a commercial pre-mixed hydraulic lime-based mortar was used for the joints. The curved shape of arches together with the advantages associated to the use of glass instead of carbon fibers when dealing with masonry, have led to the adoption of glass FRP strips bonded externally to masonry, either at extrados or intrados surfaces.

Twelve arch models were constructed using the geometrical half-scale in order to optimize expenses related to raw materials and workmanship, as well as to achieve a faster construction process and a better controlled test setup. The use of scaled models in experiments designed to represent reality usually requires the adoption of certain similarity rules, which should be selected according to the most relevant forces related with the 
phenomenon under analysis. In general, a geometrical scale is adopted for the model, whereas the other scales are easily derived from relevant similarity laws. When dealing with the testing of masonry structures, both Froude's and Cauchy's similarity laws are typically considered. In addition, these similarities usually have important consequences on the test setup. For example, considering that the scaled model is usually built with the same material as the prototype, a major consequence is the need to add mass to the scale model in order to fulfill the specific mass scale. However, the purpose related with the use of scaled models within this work is not to perform a scale analysis, but solely to achieve a faster construction process and an easier testing setup. In addition, it would very difficult, if not impossible, to scale adequately the mechanical properties of the epoxy resin used to bond the FRP material. The quality of the results is not affected by not using similarity laws and the results remain valid for the use of numerical and analytical tools, even if results cannot be directly extrapolated to real arches.

\section{Characterization of materials}

The mechanical properties of masonry were assessed trough the compressive testing of ten representative masonry prisms of dimensions $163 \times 100 \times 50 \mathrm{~mm}^{3}$, made of five stacked bricks. An average compressive strength of $9.1 \mathrm{~N} / \mathrm{mm}^{2}(\mathrm{COV}=16 \%)$ and an average elastic modulus of $2040 \mathrm{~N} / \mathrm{mm}^{2}(\mathrm{COV}=34 \%)$ were obtained $(\mathrm{COV}$ represents the statistical coefficient of variation). Tests performed on eight cylindrical mortar specimens with dimensions $\varnothing 50 \times 110 \mathrm{~mm}^{2}$ provided an average compressive strength of $7.3 \mathrm{MPa}(\mathrm{COV}=8 \%)$. The mechanical performance of the epoxy resin and of the fibers was assessed by means of direct tensile tests carried out on five specimens. Average tensile strength values of $48.6 \mathrm{~N} / \mathrm{mm}^{2}(\mathrm{COV}=9 \%)$ and $1473 \mathrm{~N} / \mathrm{mm}^{2}(\mathrm{COV}=15 \%)$ were measured for the resin and for the fibers, respectively. Regarding the elastic modulus, average values of $3670 \mathrm{~N} / \mathrm{mm}^{2}(\mathrm{COV}=8 \%)$ and $80160 \mathrm{~N} / \mathrm{mm}^{2}(\mathrm{COV}=4 \%)$ were registered for the resin and for the fibers, respectively. Appropriate ASTM standards were adopted to determine all the properties provided. From the values presented, the large difference in terms of stiffness of the materials becomes evident, i.e. the fiber's elastic modulus is roughly forty times larger than the masonry one. If carbon fibers were chosen, the elastic modulus ratio would surpass one hundred, which makes clear the option for a relatively low stiffness strengthening material. In addition, glass fibers are less expensive than carbon ones. Although carbon fibers seem to behave mechanically worse than glass fibers when combined with masonry, they have better resistance to creep and present better durability features. 
Experiments included also the characterization of tensile and shear bond strengths between FRP and masonry by means of pull-off and single-lap shear tests aiming at gaining insight into the behavior of the FRPmasonry interface, which detailed results can be found elsewhere (Basilio, 2007).

\section{Tests on arches}

The geometry adopted for the arches is illustrated in Figure 2. Each arch specimen was fabricated with 59 brick courses, disposed in a single ring, and characterized by a $750 \mathrm{~mm}$ internal radius, $450 \mathrm{~mm}$ width and $50 \mathrm{~mm}$ thickness. The mortar joints were kept with a constant intrados thickness of approximately $10 \mathrm{~mm}$. All arches were built under the testing frame, over a rigid wooden mould and using two concrete blocks fixed to the strong floor as supports. In this way, the arches reached an effective internal span of $1467 \mathrm{~mm}$ (thickness/span ratio of 1/29) and an effective internal rise of $593 \mathrm{~mm}$ (rise/span ratio of 0.40 ), resulting in segmental arches of $156^{\circ}$. Two steps of the construction sequence are represented in Figure 3. The wooden mould was carefully removed about one week after the construction, see Figure 3b, and the GFRP strips, if any, were externally bonded to the masonry substrate.

Four different sets of arches were studied, as represented in Table 1. The first set was composed by two reference arches without any strengthening (US1 and US2), whose results were used to assess the performance of the strengthened solutions. The other three sets are composed by arches with different strengthening arrangements. The definition of the strengthening width to be used was based on a previous numerical analysis (Basilio et al. 2004), aiming at optimizing the amount of fibers used with respect to the expected increase in strength. Strengthening was always composed by two equal strips placed symmetrically at the quarter width of arches, as shown in Figure 4, in order to obtain a uniaxial arch behavior as much as possible.

Considering that arches US1 and US2 were not tested up to their complete failure, it became possible to strengthen them by means of a localized strengthening arrangement composed of two GFRP strips of $80 \mathrm{~mm}$ width each, placed over the hinges at either the intrados or the extrados (second set - specimens LS1 and LS2), as illustrated in Figure 4a.

The third set was composed by four undamaged arches strengthened with two continuous GFRP strips of $50 \mathrm{~mm}$ width each at the intrados (specimens CSI1 to CSI4), see Figure 4b. Literature points out the detachment of the fibers from the masonry subtract as the major cause of failure for intrados strengthening. To face this problem, it was decided to use spike anchors in two of the arches (CSI3 and CSI4). Considering the strengthening solution used in this work, any anchor system to be used has to be compatible with the strengthening material itself and it should be able to prevent any possible stress concentrations from happen. 
Therefore, spike anchors made of dry glass fibers were used, aiming at obtaining flexible GFRP-based spike anchors. Each spike was inserted into a predrilled $6 \mathrm{~mm}$ diameter hole comprising the full thickness of the arch (i.e. of a brick). Afterwards, the hole was filled with epoxy resin and the remaining dry fibers were fanned out over the strips, at intrados, and over the masonry surface, at extrados, and then resin was applied to the dry fibers at both intrados and extrados surfaces. Four aligned spike anchors, symmetrically distributed in relation to the load point, were used in each strip covering an internal perimeter of $415 \mathrm{~mm}$.

In the fourth and last set, four undamaged arches were continuously strengthened at the extrados, as represented in Figure 4c. Existing experimental results show that failure of arches strengthened at the extrados is mainly due to sliding along a mortar joint, however, an increase of the FRP area might delay, or even avoid, this type of failure. Therefore, within this set, two arches were strengthened with two GFRP strips of 50 mm width each (specimens CSE1 and CSE2), while the other two arches were strengthened with two GFRP strips of 80 mm width each (specimens CSE3 and CSE4).

The application of the strengthening was carried out using the typical wet layup technique, detailed as follows: (1) smooth out of irregularities, as mortar excess in the joints, and cleaning of all extraneous materials to improve adhesion; (2) application of an epoxy primer on the masonry substrate and wait until it becomes tacky; (3) application of putty filler to level the masonry surface, when necessary; (4) application of a first layer of epoxy resin to the surface; (5) application of the GFRP strips (0.149 mm thickness) with fibers parallel to the arch directrix; (6) application of a second layer of epoxy resin to duly impregnate the fibers. Only a single layer of fibers was applied to arches. All the steps were carried out following the recommendations and rules of good practice provided by the manufacturer.

The arches were tested under displacement control, aiming at the characterization of the softening behavior. For that, a linearly uniform transverse vertical load was applied at the quarter span, see Figure 2, through a rigid steel beam, while the arch displacement beneath the load was controlled in a monotonic fashion at an increasing rate of $3 \mu \mathrm{m} / \mathrm{s}$. Although most real arches may have significant dead loads applied at their extrados, here it was decided not to apply other loads than the transverse concentrated load in order to reduce the number of influencing parameters and, thereby, to keep the test setup as simple as possible. Moreover, the influence of dead load applied at extrados (among other parameters) can be studied numerically, after calibration of an adequate numerical model.

The load was recorded by means of the servo-controlled actuator load cell with a $25 \mathrm{kN}$ load capacity, while the arch deflection was monitored by six LVDTs placed at relevant locations. One LVDT was used to control the 
actuator's movement. Three LVDTs were placed at mid span and at both quarter span locations to monitor deflections. The other two LVDTs were located at springings (bottom bricks) to monitor possible displacements along the supports.

Tests were stopped after the formation of the corresponding failure modes and previously to the occurrence of uncontrolled failure whenever possible. Insignificant displacements were recorded at the springings, thus confirming that arch displacements along the supports did not take place. Tests were carried out approximately two weeks after construction of the arches, so that mortar strength had an adequate value. A more detailed description of the test setup can be found in Basilio (2007).

\section{TEST RESULTS}

\section{Unstrengthened arches}

The two specimens tested without strengthening (i.e. arches US1 and US2) presented a similar structural behavior, essentially characterized by the development of a four-hinge mechanism. Figure 5a illustrates the location of the four hinges, numbered according to the formation sequence, whereas Figure $5 \mathrm{~b}$ shows one of them. The relation between vertical load and vertical displacement beneath the load is depicted in Figure 6a, while the peak load of each specimen is listed in Table 2. Despite the kinematic resemblance observed in the two tests, and as expected for unreinforced masonry, differences can be detected, namely in terms of pre-peak stiffness and maximum load achieved. A possible cause of the slight difference on the peak load may be a variation of the tensile strength of mortar. In both cases, failure occurred suddenly, for small displacements and just after reaching the maximum load. Considering the role of mortar in the behavior of the arch, a weaker mortar may originate a less unstable post-peak response. An important feature is the absence of ductility in both specimens.

\section{Localized strengthening}

Since arches US1 and US2 did not collapse in a uncontrolled way, GFRP strips were applied locally over hinges H1, H3 and H4, see Figure 5a. Strips had a length of $530 \mathrm{~mm}$ (approximately one fourth of the average arch perimeter) and were centered with the hinges, as represented in Figure 7a. These two strengthened specimens, obtained directly from specimens US1 and US2, are here labeled as LS1 and LS2, respectively.

The use of a strengthening strategy aiming at repairing the existing hinges did not avoid the formation of a new four-hinge mechanism, see Figure 7a. The GFRP strips were able to prevent the re-opening of the existent 
cracks but new hinges appeared beyond the strip length instead, as shown in Figure 7b. The formation of new hinges far from their typical locations, enforced by the presence of the fibers, promoted an increase of the peak load in both arches. The corresponding load-displacement diagrams are shown in Figure 6b. The average increase reached by the local strengthening of the damaged arches is about $76 \%$, see also Table 2 .

For a better comparison, the results exhibited in Figure 6 are rearranged in Figure 8 to highlight the structural response of the specimens. As it can be observed, the reinforcement did change neither the pre-peak stiffness nor the fragile behavior of the unstrengthened specimens. Besides the load capacity increase, also a slightly larger post-peak branch was possible to attain.

\section{Continuous intrados strengthening}

Collapse modes different from the four-hinge mechanism were expected for the arches strengthened with continuous strips. The presence of the fibers, either at extrados or intrados surfaces, would prevent the fourth hinge from occur.

For the continuous strengthened specimens at intrados, the failure mode observed is illustrated in Figure 9a. Two of the hinges were formed at the supports and the third one appeared on the right half of the arch. Failure was dictated by the successive detachment of the two strips and involved the ripping of a thin layer of brick, as shown in Figure 9b. Pull-off tests performed by the authors on strengthened masonry prisms, involving simultaneously two bricks and a mortar joint, have confirmed that the tensile strength of the FRP-masonry interface is higher than the tensile strengths of the brick and of the mortar (Basilio, 2007). All pull-off specimens failed due to the ripping of a thin layer of brick and mortar. The debonding phenomenon observed in specimens CSI1 and CSI2 is due to the normal tensile stress at the FRP-masonry interface, which depends on the FRP tensile stress level and on the arch curvature. Taking into account that curvature is constant in this case, the critical tensile stresses at the FRP-masonry interface appear where the FRP tensile stress assumes high values, i.e. in cross-sections subjected to high bending moments,. For arches loaded at the quarter span, detachment typically occurs close to the point of application of the load.

Regarding the global load-displacement response, noticeable increase in terms of load capacity were possible, as illustrated by the responses depicted in Figure 10. Here, the abrupt drops in load due to the detachment of the strips took place for very large deformations. In all specimens the strengthening did not increase the initial stiffness. On average, the load capacity of the specimens without spike anchors (i.e. specimens CSI1 and CSI2) is increased by 165\%, see Table 2, and the maximum load was achieved for a displacement of about thirty five times greater than the one corresponding to the specimens without 
strengthening, see Figure 10a. Despite the occurrence of the first hinge for different load values, both specimens presented a quite similar behavior at failure.

The differences regarding the additional use of spike anchors (specimens CSI3 and CSI4) are visible in Figure 10b, where the displacement associated to collapse roughly doubles the one obtained without spikes. Moreover, Table 2 shows a slight increase in load capacity, from $165 \%$ to $174 \%$. These results demonstrate that the handmade spike anchors were able to control tensile stresses at the FRP-masonry interface and, thus, to increase the collapse load and to delay the fibers detachment (i.e. to increase ductility).

\section{Continuous extrados strengthening}

For the continuous strengthened specimens at extrados (CSE1 to CSE4), the failure mechanism developed during testing is illustrated in Figure 11. In these experiments, the first hinge was formed beneath the applied load, whereas the other two hinges appeared afterwards at the supports. Failure was characterized by the sliding of one part of the arch with respect to the other, along a mortar joint close to the right support, see Figure 11b, due to insufficient shear resistance.

The load-displacement curves are included in Figure 12. Also within this set, the strengthening did not increase the stiffness of specimens. For specimens with the narrower strips (CSE1 and CSE2) a load increase of about $89 \%$ is achieved comparatively with the unstrengthened specimens, however not as higher as the increase enabled by specimens CSI, see also Table 2. This difference in load capacity is not due to a considerable higher shear strength provided by the intrados strengthening technique. Instead, it is related to distinct internal forces distributions along the directrix of the arch. The distribution of internal forces depends on the position of the thrust line, which, in turn, is a function of the strengthening option adopted. Valluzzi et al. (2001) have shown that for catenary shaped arches (rise/span ratio of 0.37 , which is close to the ratio used in this work), loaded at the quarter span (left half), shear forces at the right support reach much higher values for the extrados strengthening option than for the intrados case.

The maximum load capacity is achieved for a displacement approximately twenty five times greater than the one corresponding to specimens US. A very important feature is the long post-peak branch recorded, which provides the structure with important ductility behavior. In fact, the displacement previously to failure is higher than the corresponding one measured in specimens CSI, even considering the use of spike anchors.

The increase of the FRP cross-section area (specimens CSE3 and CSE4) did not cause important changes on the structural response. Apart from a moderate increase in strength, from $89 \%$ to $105 \%$ (see Table 2), CSE 
specimens exhibited similar behavior and collapse modes. These results show that the use of additional FRP material (an increase of 60\%) does not necessarily imply major improvements on the response.

\section{Global comparison}

Both continuous strengthening at intrados and extrados allowed improvements on arch performance, in terms of load capacity and displacement previously to rupture. In order to better illustrate these enhancements, three new ratios are here defined as follows:

- relative strength: ratio between the average strength attained in each strengthening arrangement and average strength measured for the arches without strengthening (using values provided in Table 2);

- relative displacement: ratio between the average displacement prior to the occurrence of major drops in load in each strengthening arrangement (termed as average sustained displacement in Table 2) and the one corresponding to the arches without strengthening (using values provided in Table 2);

- relative GFRP area: ratio of the GFRP cross-section area used in each strengthening arrangement by the masonry cross-section area (using values provided in Table 1).

Figure 13a represents the relation between the relative strength and the relative GFRP area, while Figure $13 \mathrm{~b}$ illustrates the relation between the relative displacement and the relative GFRP area. The intrados strengthening represents the best option to promote the increase in load capacity, but the additional use of spike anchors did not improve the collapse load significantly, see Figure $13 \mathrm{a}$. Despite a $60 \%$ additional utilization of GFRP material, the extrados strengthening reached only $77 \%$ of the maximum load achieved by the intrados strengthening (without spikes). When looking at the structural ability to deform under sustained loading, which may be identified as a measure of ductility, the extrados strengthening strategy showed higher values, for both strip widths, see Figure 13b. However, the additional use of spike anchors within the intrados strengthening allowed moving roughly from $45 \%$ to $85 \%$ of the average deformation capacity of the extrados strengthening, which constitutes a remarkable feature.

The trend lines represented in Figure 13 (termed as CSE trend) were obtained as the best-fit curves to experimental results relative to specimens strengthened at the extrados and to unstrengthened specimens (i.e. three pairs of data points). These trends seem to show that the strip width chosen for specimens CSE1 and CSE2 $\left(2 \times 50 \mathrm{~mm}^{2}\right)$ is close to an optimum value in the sense that further increments in width do not provide significant increments in load capacity or ductility. However, these trends must be looked at with care since only three pairs of data points have been used. 


\section{Comparison with previous works}

Differences in materials, specimens' shapes, strengthening configurations and lack of harmonization of experimental procedures makes the comparison of the results described here with results from other authors difficult. However, a review of the most well known experimental works carried out on masonry arches strengthened with FRP composites puts into evidence some interesting aspects.

The application of externally bonded FRP reinforcements (at extrados or intrados substrate) causes always an increase of the collapse load (Valluzzi et al. 2001, Foraboschi 2004, Baratta and Corbi 2007, Briccoli Bati et al. 2007, De Lorenzis et al. 2007). This expected result was also observed here. However, the characterization of the post-peak behavior, as presented in this work, is hardly available in literature.

In the case of partial or localized strengthening, failure is due to the occurrence of a four-hinge mechanism, as for unstrengthened arches, where hinges are formed at different places than in the unstrengthened specimens (Foraboschi 2004), which is in agreement with the results described in this paper. This strengthening strategy is almost not considered in literature.

For arches strengthened at the extrados, masonry sliding is the most common failure mode. Typically, sliding occurs close to the supports and along a mortar joint, due to insufficient shear strength (e.g. Valluzzi et al. 2001, Foraboschi 2004). Baratta and Corbi (2007) concluded that in the case of extrados strengthening, the behavior is highly ductile, as reported in this paper, while Foraboschi (2004) reported that the extrados strengthening technique allow a more brittle behavior if compared to the intrados one.

For arches strengthened at the intrados, the critical feature is the occurrence of detachment of the reinforcing material (Valluzzi et al. 2001, Foraboschi 2004, Baratta and Corbi 2007, Briccoli Bati et al. 2007), although the detachment failure mode may be accompanied by hinge collapse mechanism. Foraboschi (2004) and Baratta and Corbi (2007) reported a higher increase of the collapse load for intrados strengthening, as in this work, whereas Valluzzi et al. (2001) found such increase for arches strengthened at the extrados. Results concerning the use of spike anchors on arches are almost absent from literature, however its use can be effective in preventing debonding of FRP sheets applied at the intrados of a masonry arch (De Lorenzis et al. 2007). Additionally, the use of polymeric composites causes the ripping of a thin layer of brick (Foraboschi 2004), while the option for a cement matrix may prevent such behavior (Briccoli Bati et al. 2007). 


\section{CONCLUDING REMARKS}

The experimental performance of half-scaled segmental brick masonry arches, unstrengthened and strengthened with GFRP strips under different arrangements, has been presented and discussed in the paper. The arches without strengthening failed through the formation of a typical four-hinge mechanism. Collapse occurred in a brittle fashion for very small displacements. All strengthening arrangements employed led to an increase of the load capacity, but localized strengthening does not seem to be a suitable strategy as it does not change the initial failure mechanism.

The experimental results show that continuous strengthening strategies provide an enhanced arch behavior with respect to the unstrengthened specimens, allowing important increases in terms of maximum load applied and displacement prior to failure. In addition, continuous strengthening was able to prevent the formation of hinge-based failure modes. Thereby, new dominant failure modes were observed.

Arches strengthened at intrados failed due to the detachment of the fibers from the masonry substrate, causing the ripping of a thin layer of brick and mortar. This debonding phenomenon is originated by the higher values of the normal tensile stress at the FRP-masonry interface. The use of flexible GFRP-based spike anchors was effective in delaying the detachment of the GFRP strips, allowing doubling the average displacement at failure. For arches strengthened at extrados, failure occurred due to sliding along a mortar joint close to the right support. This type of failure occurs because the presence of FRP increases the flexural strength of the arch and it allows the outward movement and a significant inclination of the thrust line with respect to the cross-section.

For a given GFRP amount up to approximately $0.06 \%$ of the arch cross-section area, experiments show that strengthening at the intrados is the most effective option to increase the strength of the arch. On the other hand, strengthening applied at the extrados provides the higher deformation capacity prior to failure, endowing arches with an important ductility behavior. The experimental results presented in this paper were obtained under simple and controlled setups and procedures, thus constituting an important database on the behavior of masonry arches, able to be used in the calibration of analytical and numerical models for the simulation of the structural behavior of brick masonry arches up to failure.

Despite the available results in literature concerning the structural behavior of arches strengthened with composite materials, a harmonization of procedures together with further research are needed in order to confirm trends and to clarify issues apparently in contradiction, as those described above in the paper. 


\section{ACKNOWLEDGMENTS}

The financial support provided by the Portuguese Science and Technology Foundation through the POCTI/ECM/38071/2001 project is gratefully acknowledged. FRP composites and pre-mixed mortar used in the experiments were provided by BETTOR MBT and MAPEI, respectively, to whom the authors are grateful. The assistance of the technicians during the construction of all specimens is highly appreciated. The second author wishes to express his gratitude to CONACYT for the scholarship granted.

\section{REFERENCES}

Albert, M.L., Elwi, A.E., Cheng, R.J.J. (2001). "Strengthening of unreinforced masonry walls using FRPs", J. Compos. for Constr., 5(2), 76-84.

Baratta, A., Corbi, O. (2007). "Stress analysis of masonry vaults and static efficacy of FRP repairs", International Journal of Solids and Structures, 44, 8028-8056.

Basilio, I. (2007). "Strengthening of arched masonry structures with composites materials", PhD Thesis, Universidade do Minho, Guimarães, Portugal. Available at www.civil.uminho.pt/masonry.

Basilio, I., Oliveira, D.V., Lourenço, P.B. (2004). “Optimal FRP strengthening of masonry arches”, Proc. 13th International Brick/Block Masonry Conference, Amsterdam, 361-370.

Briccoli Bati, S., Rovero, L. (2001). "Experimental validation of a proposed numerical model for the FRP consolidation of masonry arches", Proc. 3rd Int. Seminar on Structural Analysis of Historical Constructions, Universidade do Minho, Portugal, 1057-1066.

Briccoli Bati, S., Rovero, L., Tonietti, U. (2007). "Strengthening masonry arches with composite materials", J. Compos. for Constr., 11(1), 33-41.

De Lorenzis, L., Dimitri, R., La Tegola, A. (2007). "Reduction of the lateral thrust of masonry arches and vaults with FRP composites”, Construction and Building Materials, 21, 1415-1430.

Ehsani, M.R., Saadatmanesh, H., Al-Saidy, A. (1997). "Shear behavior of URM retrofitted with FRP overlays", J. Compos. for Constr., 1(1), 17-25.

Foraboschi, P. (2004). “Strengthening of masonry arches with fiber-reinforced polymer strips”, J. Compos. for Constr., 8(3), 191-202.

Heyman, J. (1982). “The masonry arch”, Ellis Horwood, Ltd., New York. 
ICOMOS (2001). "Recommendations for the analysis, conservation and structural restoration of architectural heritage", International Scientific Committee for Analysis and Restoration of Structures of Architectural Heritage, Paris.

Kolsh, H. (1998). "Carbon fiber cement overlay system for masonry strengthening”, J. Compos. for Constr., 2(2), 105-109.

Saadatmanesh, H. (1994). "Fiber composites for new and existing structures", ACI Struct. J., 91(3), 346-354.

Schwegler, G. (1994). "Strengthening of masonry with fiber composites", PhD Thesis, Federal Institute of Technology, Zurich, Switzerland.

Triantafillou, T.C. (1998). "Strengthening of masonry structures using epoxy-bonded FRP laminates", J. Compos. for Constr., 2(2), 96-104. Errata in J. Compos. for Constr., 2(4), 203.

Valluzzi, M.R., Valdemarca, M., Modena, C. (2001). "Experimental analysis and modeling of brick masonry vaults strengthened by FRP laminates”, J. Compos. for Constr., 5(3), 163-169. 


\section{LIST OF TABLES CAPTIONS}

Table $1-\quad$ Identification of the four sets of arches tested and amount of GFRP used in each specimen.

Table $2-\quad$ Experimental results concerning the maximum load achieved, strength increase and average sustained displacement provided by the different GFRP strengthening strategies. 
Table 1- Identification of the four sets of arches tested and amount of GFRP used in each specimen.

\begin{tabular}{|c|c|c|}
\hline $\begin{array}{l}\text { Strengthening } \\
\text { arrangement }\end{array}$ & Specimen & $\begin{array}{l}\text { Strengthening } \\
\text { width [mm] }\end{array}$ \\
\hline \multirow{3}{*}{ Unstrengthened } & US1 & 0 \\
\hline & & \\
\hline & US2 & 0 \\
\hline \multirow{2}{*}{$\begin{array}{c}\text { Localized } \\
\text { strengthening }\end{array}$} & LS1 & $2 \times 80$ \\
\hline & LS2 & $2 \times 80$ \\
\hline \multirow{4}{*}{$\begin{array}{l}\text { Continuous strengthening } \\
\text { (intrados) }\end{array}$} & CSI1 & $2 \times 50$ \\
\hline & CSI2 & $2 \times 50$ \\
\hline & $\mathrm{CSI} 3^{(*)}$ & $2 \times 50$ \\
\hline & $\mathrm{CSI} 4^{(*)}$ & $2 \times 50$ \\
\hline \multirow{4}{*}{$\begin{array}{l}\text { Continuous strengthening } \\
\text { (extrados) }\end{array}$} & CSE1 & $2 \times 50$ \\
\hline & CSE2 & $2 \times 50$ \\
\hline & CSE3 & $2 \times 80$ \\
\hline & CSE4 & $2 \times 80$ \\
\hline
\end{tabular}

${ }^{(*)}$ - Handmade GFRP-based spike anchors were used in addition to the strips. 
Table 2- Experimental results concerning the maximum load achieved, strength increase and average sustained displacement provided by the different GFRP strengthening strategies.

\begin{tabular}{|c|c|c|c|c|c|}
\hline $\begin{array}{l}\text { Strengthening } \\
\text { arrangement }\end{array}$ & Specimen & $\begin{array}{l}\text { Maximum } \\
\text { load }[\mathrm{kN}]\end{array}$ & $\begin{array}{c}\text { Average } \\
\text { value }[\mathrm{kN}]\end{array}$ & $\begin{array}{l}\text { Strength } \\
\text { increase }\end{array}$ & $\begin{array}{l}\text { Average sustained } \\
\text { displacement [mm] }\end{array}$ \\
\hline \multirow{3}{*}{ Unstrengthened } & US1 & 1.43 & \multirow{3}{*}{1.68} & \multirow{3}{*}{---- } & \multirow{3}{*}{0.45} \\
\hline & & & & & \\
\hline & US2 & 1.92 & & & \\
\hline \multirow{2}{*}{$\begin{array}{c}\text { Localized } \\
\text { strengthening }\end{array}$} & LS1 & 2.73 & \multirow{2}{*}{2.96} & \multirow{2}{*}{$+76 \%$} & \multirow{2}{*}{0.89} \\
\hline & LS2 & 3.18 & & & \\
\hline \multirow{6}{*}{$\begin{array}{l}\text { Continuous } \\
\text { strengthening } \\
\text { (intrados) }\end{array}$} & CSI1 & 4.63 & \multirow{3}{*}{4.45} & \multirow{3}{*}{$+165 \%$} & \multirow{3}{*}{15.50} \\
\hline & & & & & \\
\hline & CSI2 & 4.26 & & & \\
\hline & CSI3 & 5.41 & \multirow{3}{*}{4.61} & \multirow{3}{*}{$+174 \%$} & \multirow{3}{*}{28.75} \\
\hline & & & & & \\
\hline & CSI4 & 3.81 & & & \\
\hline \multirow{6}{*}{$\begin{array}{l}\text { Continuous } \\
\text { strengthening } \\
\text { (extrados) }\end{array}$} & CSE1 & 2.51 & \multirow{3}{*}{3.17} & \multirow{3}{*}{$+89 \%$} & \multirow{3}{*}{35.90} \\
\hline & & & & & \\
\hline & CSE2 & 3.82 & & & \\
\hline & CSE3 & 3.62 & \multirow{3}{*}{3.44} & \multirow{3}{*}{$+105 \%$} & \multirow{3}{*}{32.70} \\
\hline & & & & & \\
\hline & CSE4 & 3.26 & & & \\
\hline
\end{tabular}




\section{LIST OF FIGURES CAPTIONS}

Figure 1 - Typical four-hinge failure mechanism of a masonry arch submitted to an asymmetrical concentrated load (hinges occur on the boundary of the cross-section, either at the intrados or extrados).

Figure $2-$ Adopted arch geometry and load arrangement (front view).

Figure 3 - Two of the phases involved in the construction of the arches: (a) laying of bricks; (b) removal of the wooden mould.

Figure 4- Location of strengthening: (a) localized strengthening; (b) continuous intrados strengthening; (c) continuous extrados strengthening.

Figure 5 - Unstrengthened arches: (a) typical four-hinge failure mechanism developed; (b) extrados view of hinge $\mathrm{H} 3$.

Figure 6 - Vertical load-displacement diagrams for the unstrengthened arches: (a) before strengthening (arches US1 and US2); (b) after localized strengthening (arches LS1 and LS2). Note the use of different scales to represent the load.

Figure 7 - Localized strengthening: (a) failure mechanism developed; (b) extrados view of hinge H3.

Figure 8 - Vertical load-displacement diagrams before and after local strengthening: (a) arch US1 / LS1; (b) arch US2 / LS2.

Figure 9 - Continuous intrados strengthening: (a) failure mode observed; (b) detachment of the GFRP strips at the end of the test.

Figure 10 - Vertical load-displacement diagrams for the intrados strengthened arches: (a) arches CSI1 and CSI2; (b) arches CSI3 and CSI4 (arch CSI2 is also included to show up the use of different scales to represent the displacement).

Figure 11 - Continuous extrados strengthening: (a) failure mode observed; (b) sliding along a mortar joint close to the right support.

Figure 12 - Vertical load-displacement diagrams for the extrados strengthened arches: (a) arches CSE1 and CSE2; (b) arches CSE3 and CSE4 (arch CSE2 is also included).

Figure 13 - Efficiency of the different strengthening arrangements: (a) in terms of relative strength; (b) in terms of relative displacement. 